where acute intermittent porphyria is very common. A third approach to this problem would be if we could state that the increase in faecal porphyrins characteristic of South African porphyria could be found in members of families with what is believed to be acute intermittent (Swedish) porphyria. So far this has not been possible. Another problem that we have been trying to solve is the following. Could it be that the large number of persons with latent porphyria in Sweden belonging both to PAI and to PV families have about the same biochemical picture, or is there a sharp demarcation line between these groups? We have therefore plotted the data for faecal porphyrins from 18 latent members of our three variegata families in Sweden, together with the data from some persons with latent PAI. This has also been done with urinary ALA and PBG values (Figs. 6 and 7). The graphs clearly show that

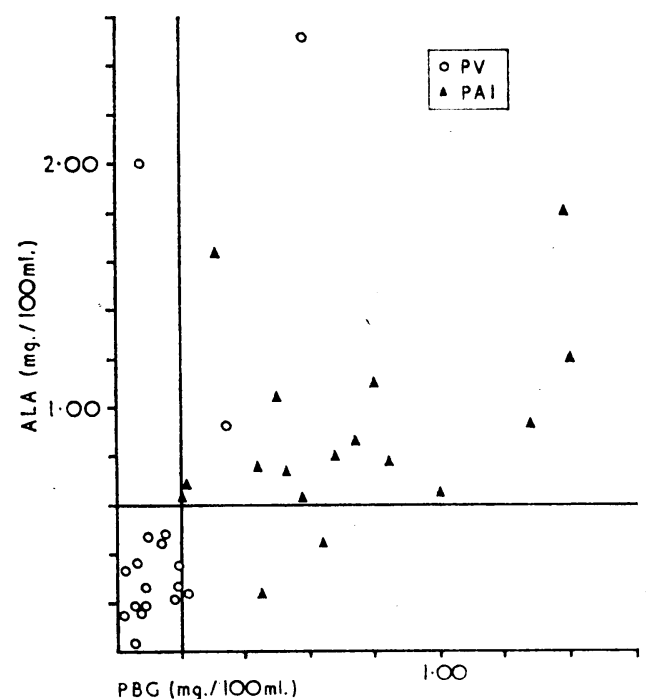

Fig. 7.-Urinary excretion of ALA and PBG in 18 patients with latent $P V$ and in 17 patients with latent PAI. Inserted vertical and horizontal lines indicate upper limit of normal range of excretion of $\mathrm{PBG}$ and ALA respectively. the two diseases have different excretory patterns: PV with relatively high faecal porphyrins but mostly normal urinary ALA and PBG, PAI with near normal faecal porphyrins but high ALA and PBG in the urine.

Two different interpretations of the findings regarding these disease pictures have been given. One interpretation, represented among others by Dean, Barnes, and the Malmö group, is that they are fundamentally different. The other, with Watson (1960) as the chief advocate, is that they are "mixed" and that some members for some reason or other also develop skin sensitivity. The most elegant way to prove that the diseases are different would be if they could be shown to be linked and not linked to some well-defined heritable condition. Such studies on our very extensive material are now in progress.

\section{Summary}

The three first families with porphyria variegata from Sweden are described. Two of them are descended from Småland, in southern Sweden. In spite of tracing the families back to the beginning and middle of the nineteenth century no relationship has been found with any family in which acute porphyria intermittens has occurred. In all, 24 cases of porphyria variegata are reported -5 manifest and 19 latent.

Supported by a grant to J. Waldenström and B. Haeger-Aronsen from the Swedish Medical Research Council.

\section{REFERENCES}

Dean, G. (1953). Brit. med. F., 2, 1291.

(1963). The Porphyrias. London.

(1963). The Porphyrias. Londion. med. 7., 2, 89.

and Barnes, H. D. (1955). (1958). Ibid., 1, 298. . Afr. med. 33, 246.

Eales, (1959). S. Afr. med.

Eales, L. (1956). Ibid., 30, 924. . Med., 6, 63

Haeger-Aronsen, B. (1962). Scand. \%. clin. Lab. Invest., 14, 397.

Hamnström, B. Haeger-Aronsen, B., and Waldenström, J. (1964). Lecture in Svenska föreningen för invärtes medicin: Porphyria variegata i Sverige.

Whaldenstrom, J. (1937). Acta med. scand., Suppl. No. 82.

Waldenstrom, J. (1937). Acta med. scand., Suppl. No. 82.

- and Haeger-Aronsen, B. (1963). Brit. med. ${ }^{7} .$,

Watson, C. J. (1960). New Engl. f. Med., 263, 1205.

\title{
Double-blind Experiments on the Effect of a Peanut Extract on the Bleeding Incidence in 92 Haemophiliacs*
}

\author{
M. VERSTRAETE, $†$ M.D. ; C. A. J. RUYS, $\ddagger$ M.D.
}

Brit. med. F., 1967, 4, 453-456

It is the fate of patients afflicted with a life-long disease to be subjected to therapeutic trials with new drugs or substances, of which the possible impact on the underlying diseases is not always apparent. A classical example is haemophilia ; a long list of drugs has stirred a fleeting hope in patients affected with this bleeding disorder when the new therapy coincides with one of their cyclic symptomless periods.

The fortuitous observation by a haemophilic patient that while consuming daily roasted peanuts the tenderness of an acute knee haemarthrosis seemed to subside more rapidly has

- Study organized with the kind co-operation of Belgian and Dutch groups interested in the treatment of haemophilia. Belgium Louvain (M. Verstraete, J. Vermylen, and $H$. Van Itterbeek) Netherlands: Ámsterdam (S. van Creveld, I. A. Mochtar, and J. Jonker), Leiden (E. A. Loeliger, A. Hensen, N. Fekkes, and J. J. Leeksma), Zevenaar (F. B. M. Verhey).

Assiate Professor of Medicine, University of Louvain, Belgium. Anvestigator ACF Amsterdam, Netherlands.

From the Laboratory of Blood Coagulation and Proteolysis, Department of Medicine, University of Louvain, Belgium. focused attention to a possible beneficial factor in peanuts for the treatment of haemophilia (Boudreaux et al., 1960). Largely because of untimely and uncontrolled rumours in the lay press, many haemophiliacs started experimenting on their own with any available source of peanuts-for example, commercial peanut butter, roasted and raw peanuts, or peanut flour.

The discovery of antifibrinolytic properties in peanuts, together with a possibly increased fibrinolytic potential in haemophiliacs (van Creveld et al., 1961), were thought to offer a reasonable basis for further investigation; also because in isolated studies a beneficial effect of peanuts or peanut extracts on the bleeding incidence of haemophilic patients continued to be reported (Brüster, 1961 ; Bisordi, 1964). Unfortunately these investigations were conducted in a limited number of patients and with a variety of peanut preparations (raw or roasted peanuts, peanut butter, peanut flour, or screw-pressed extracted peanut meal) or peanut extracts (crude peanut oil, hexane-extracted roasted peanuts, or $95 \%$ ethanol extract of peanut flour). 
As no double-blind trial on a large group of haemophiliacs had apparently been instituted, it was decided to organize a joint study in Belgium and in the Netherlands, making use of a uniform protocol and a single batch of a given peanut preparation.

\section{Design of the Double-blind Study}

\section{Selection of Patients}

Only seriously affected haemophiliacs (type A or B) were admitted to this study. In addition to clinical judgement, it was considered that a coagulation time of whole blood over 45 minutes, as assessed with a standardized thromboelastographic method, was a satisfactory criterion, as it would be observed only in haemophiliacs with a very low level of factor VIII or IX. Indeed, it was found that an r-value of 45 minutes or more corresponds to $3 \%$ factor VIII activity or less.

The different patients were paired according to haemophilia type, age, and social class, so that two groups of patients were obtained in each centre. One group received the placebo product first during 12 weeks, followed by the experimental product during the next 12 weeks $\left(\mathrm{P}_{1}, \mathrm{E}_{2}\right)$; in the second group the order was reversed $\left(\mathrm{E}_{1}, \mathrm{P}_{2}\right)$. The pairing of the patients was made by a person who did not know the treatment group. The purpose of pairing patients according to the criteria given was to take into account the effects of other influences and to avoid a bias due to decreased or increased attention of the patient in his symptoms and the diary kept during the course of the trial.

\section{Evaluation of the Incidence of Bleeding}

All patients participating in the collaborative study were requested to visit their physician before and after every sixth week of the trial. At the first visit a questionary was explained to the patient which he had to fill in daily (diary). The first list was centred on five frequent bleeding manifestations in haemophilia (ecchymoses, haematomata, haemarthroses, haematuria, and epistaxis); 12 subsidiary questions were aimed to give a rough estimation of duration and importance of a bleeding episode. The patient was also requested to mention each time he sought medical help, was unable to attend class or work, or had to be transfused or admitted to hospital because of bleeding.

The haemophiliacs accepted in this collaborative study were not allowed to take synthetic fibrinolytic inhibitors during the course of the trial-for example, aminocaproic acid or tranexamic acid. If a haemophilic patient had to be admitted to hospital because of bleeding and needed blood transfusion, he interrupted the intake of the experimental product until discharge ; during the hospital stay the diary was not filled in. Any other drug - for example, antibiotics, laxatives, expectorants -administered at home had to be recorded daily on the information sheet. The patient was also asked to report any intercurrent disease-for example, common cold, bronchitis.

Haemophiliacs were recommended to refrain from drugs containing salicylates at any time, and particularly during this trial.

At each six-weekly visit the material under trial for the following period was handed to the patient. The physician also inquired about any possible side-effects and the subjective opinion of the patient on the value of the therapy.

Though a new supply of substance was provided every sixth week, it was arranged that placebo or peanut extract was given without interruption for 12 weeks. This rather long period was thought to be essential because peanut extract could require some time before exerting its alleged action on bleeding, which, if present, could last a few weeks after withdrawal of the drug.
At the onset 107 haemophiliacs were included in the trial. In the final study of the results 15 patients had to be excluded for a variety of reasons, such as lack of sustained co-operation, repeated administration of blood or plasma transfusions during the three-month course of the trial, or intervening illness treated with a variety of other drugs.

The final evaluation includes 67 Belgian and 25 Dutch haemophiliacs, four of them being cases of haemophilia B or Christmas disease. The distribution according to age groups was as follows: between 1 and 3 years old, 6 ( 5 haemophilia A and 1 haemophilia B); over 3 to 14 years, 38 ( 37 haemophilia $A$ and 1 haemophilia B); and over 14 years, 48 (46 haemophilia $A$ and 2 haemophilia $B$ ).

\section{Preparation and Dosage of the Peanut Extract}

The peanuts used are of South African origin (common Natal 70/80 hand-picked selected). The peanut extract was prepared and kindly made available free of charge by a pharmaceutical company. ${ }^{1}$ One single large batch of experimental product and placebo was used in this trial. Raw peanuts still containing their skin are ground and extracted with hexane until freed of the oily material (Astrup et al., 1962). An alkaline aqueous extract is prepared ( $p \mathrm{H} 6.5)$, and after centrifugation treated four times with acetone ( $p \mathrm{H}$ kept at 5.5) and the dry water residue used. Three grammes of raw peanuts yield about 100 mg. of the final powder.

The placebo powder used had the same appearance, smell, and taste as the experimental product.

The daily administered dose of this powder varied according to the age of the patient, but was always given thrice daily (between 1 and 3 years $100 \mathrm{mg}$. three times; between 3 and 14 years $300 \mathrm{mg}$. three times; and over 14 years $600 \mathrm{mg}$. three times). A daily dose of $1,800 \mathrm{mg}$. of experimental product is the equivalent of about $54 \mathrm{~g}$. of raw pindas.

\section{Results of the Statistical Analysis}

Three criteria were used in the final statistical evaluation : the frequency of ecchymoses or of all other bleeding episodes excluding ecchymoses, (epistaxis, haemarthrosis, haematuria, haematoma in muscles, bleeding in mouth and throat) and the duration of absence from school or work because of haemorrhagic incidents. From statistical analysis it appeared that no significant difference in the results for the three criteria mentioned were obtained between the 67 Belgian and 25 Dutch patients. Furthermore, the overall difference in incidence between those who took placebo first and treatment first are not significant. Subsidiary analysis by ages did not reveal a significant difference between the six classes of age groups (1-5 years, $6-10$ years, $11-15$ years, $16-20$ years, $21-30$ years, 31 years and over). Therefore as regards nationality, age, class, and trial order the material can be regarded as homogeneous and used as a single group in the final comparison between the effects of the experimental substance and the placebo.

In the left-hand columns of the three sections of the Table are given the differences in incidence for a given criterion between the experimental and placebo period $(E-P)$ for the group of 92 haemophiliacs. Negative values of $E-P$ mean a greater bleeding incidence in the placebo periods, positive values of $E-P$ correspond to a greater bleeding incidence in the active treatment period for a given patient. For the three selected criteria the mean of the differences between the treatment periods were close to zero and excludes therefore a significant difference.

${ }_{1}$ N.V. Amsterdamse Chıninefabriek, Amsterdam. 
Incidence of Ecchymoses, other Bleeding Manifestations and Duration in Days of Absence from School or Work in 92 Haemophilic Patients during Treatment with the Experimental Products $(E)$ or Placebo $(P)$

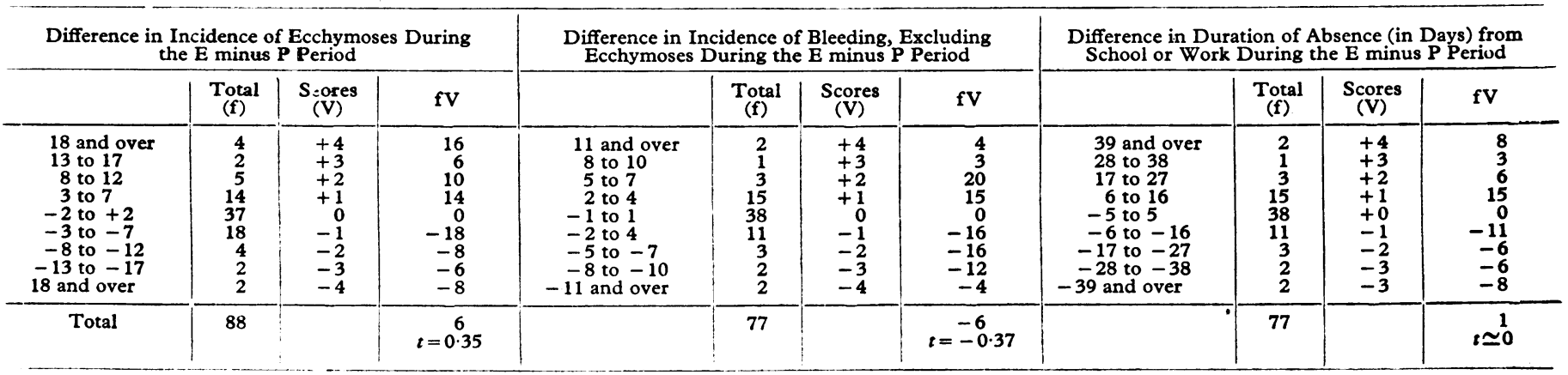

\section{Discussion}

The initial hypothesis that a genetic block of the metabolic synthesis of factor VIII could have been partially overcome by a factor present in peanuts could not be maintained, as the activity of the coagulation factors VIII and IX was found to be uninfluenced by the consumption of peanuts (Schmutzler, 1961 ; van Creveld and Mochtar, 1961 ; Brakman et al., 1962 ; Verstraete et al., 1962).

Flavanones extracted from peanut skins have a favourable effect on capillary resistance and on the bleeding times of rats (Verstraete et al., 1962). Cepelák (1965) extracted from peanut skins a potent antifibrinolytic substance which promoted haemostasis in haemophilia A and B patients as in other haemorrhagic states. Vasoconstricting compounds were also found in an ethanol extract of defatted peanuts with which a favourable clinical effect was reported (Boudreaux et al., 1960). The same investigators showed that a component of peanuts is being adsorbed into platelets resulting, after viscous metamorphosis, in a potent vasoactive activity which differs from serotonin and cannot be inhibited by atropine. Van Creveld et al. (1965), however, obtained a haemostatic effect with a peanut preparation exhibiting antifibrinolytic but no vasoconstrictor activity. More recently it was suggested that the peanut factor might enhance the platelet-plug-stabilization process, and that vasoconstriction was merely incidental to the phenomenon of platelet-pluginduced haemastasis (Frampton et al., 1966).

Astrup et al. (1961) found that peanuts and their extracts, with hexane, saline, barbital buffer, or $2 \mathrm{M}$ potassium thiocyanate, exert a powerful protease-inhibiting effect. These results were later confirmed (Schmutzler, 1961 ; van Creveld and Mochtar, 1961 ; Verstraete et al., 1962). The antiprotease activity is directed rather against the activation of plasminogen than against formed plasmin. The observation that haemophilic patients may have an increased fibrinolytic activity, as suggested by a short euglobulin lysis time (van Creveld et al., 1961), fits well with the hypothesis of Astrup et al. (1961) that an increased fibrinolytic activity which causes no harm in a normal individual could produce bleeding in a patient with an impaired haemostatic balance.

It has further been demonstrated that naturally occurring protease inhibitors, which are proteins or peptides, can pass the intestinal wall and enter the blood stream. After oral adsorption of roasted peanuts a decrease in fibrinolytic activity of euglobulin precipitate (Astrup et al., 1961 ; van Creveld and Mochtar, 1961 ; Moers and den Ottolander, 1961 ; Brakman et al., 1962) and an increased inhibitory activity against streptokinase activated human blood (Nilsson, 1960) have been ascribed to the passage of the protease inhibitor through the membranes of the intestinal villi.

In consequence a critical clinical trial with a peanut extract was thought necessary. Our double-blind trial in 92 haemophiliacs did not reveal a statistical difference in the bleeding frequency between the two periods of 12 weeks. These negative results cannot reasonably be ascribed to an improper selection of the peanut extract used; the hexane extract was prepared from raw peanuts, as it was shown that defatted unroasted peanuts have a twentyfold antifibrinolytic activity compared with roasted peanuts. Moreover, the same type of preparation was reported to be active-that is, induces a decrease of the fibrinolytic activity in the peripheral blood (van Creveld and Mochtar, 1961) and an apparent diminished bleeding incidence in haemophiliacs (Brakman et al., 1962 ; van Creveld et al., 1965). In the experiments of van Creveld and Mochtar (1961) even the same source of material (Unilever-A.C.F.) but at a lower dose (1.3 times less compared with present trial) was used.

Though it is beyond doubt that peanut extracts, when administered orally, exert an antifibrinolytic effect in the blood, the point is not proved that this inhibitory action is relevant for the prevention of bleeding in haemophiliacs. Some but not all haemophiliacs have a decreased euglobulin lysis time, and a fixed relation between this fibrinolytic activity and the occurrence of bleeding episodes has never been demonstrated (Schmutzler, 1961). Moreover, it was recently shown that peanut extracts almost devoid of antiprotease activity still maintain a haemostatic function probably related to choline or choline derivatives (Frampton et al., 1966 ; Jackson et al., 1966 ; Boudreaux, 1967). The choline content of the extract used in this trial was less than $0.22 \%$ (Boudreaux, 1967). The hypothesis that the haemostatic effect of ethanol extracts of defatted peanuts were related to their vasoconstricting properties (Boudreaux et al., 1960 ; Frampton et al., 1966) could not be studied in this trial.

Only patients with severe haemophilia were on purpose selected for this study; it was thought that the clinical evaluation of any drug in haemophilia can hardly be made in mild cases, because such patients have haemorrhagic incidents only after significant haemostatic challenge ; the severe haemophiliacs, on the other hand, have incidents of spontaneous haemorrhage.

Most of our patients claimed that their bleeding was less frequent, and that periods of relapse were milder and of shorter duration during the trial; however, these subjective observations were made also during the placebo period, while the patient received the trial substance. Many patients complained on termination of the six months' trial that the bleeding symptoms became worse. One possible explanation is that hope and better medical attention of the haemophilic patients induced by the six-weekly visits to their physicians could be responsible for this bias.

Our results are not in keeping with the experiments of Brüster (1961, 1962), who observed after the oral intake of $15 \mathrm{~g}$. of the hexane extract of peanuts a decrease in the coagulation time, an improvement in the results with the thromboplastin generation test and prothrombin consumption, and a definite haemostatic effect in five haemophiliacs $A$ and seven haemophiliacs $B$. 
With the peanut preparation evaluated in the present doubleblind trial on 92 haemophiliacs no favourable effect on bleeding could be observed. Based on these findings we would propose to refrain from recommending peanuts or their extracts as a haemostatic agent to haemophilic patients until definite proof of the beneficial effect of a given peanut preparation to the control of haemophilic bleeding is presented.

\section{Summary}

The haemostatic value of an aqueous extract of raw ground and hexane-defatted peanut kernels was evaluated in 92 severely affected haemophilic patients during a six-months double-blind trial. With the criteria selected, no statistical proved benefit on the bleeding incidence could be demonstrated during the "sctive" treatment.
REPERENCES

Astrup T Brakman, P., Ollendorff, P., and Rasmussen, J. (1961) Thrombos. Dial hes. haemorrh. (Stuttg.), $5,329$.

- and Siølin, K.-E. (1962). Nature (Lond.), 194, 980.

Bisordi, M. V. (1964). Lancet, 2, 476.

Boudreaux, H. B. (1967). Personal communication.

Boudreaux, R. M., Brandon, M., Frampton, V. L., and Lee, L. S. (1960). Arch. Biochem., 89, 276.

Brakman, P., Sjolin, K.-E., and Astrup, T. (1962). Thrombos. Diathes. haemorrh. (Stuttg.), 8, 442.

Brüster, H. (1961). Klin. W schr., 39, 1145.

Brüster, (1962). Z. Kinderheilk., 86, 462 .

Cepelák, V. (1965). Z. ges. inn. Med., 20, Suppl. p. 317.

Frampton, V. L., Lee. L. S., Morris, N. J., and Bourdreux, H. B. (1966) Thrombos. Diathes. haemorrh. (Stuttg.), 16, 265.

Jackson, B., Owen, W., and Boudreaux, H. B. (1966). Ibid., 16, 257. Moers, A. M. J., and den Ottolander, G. H. J. (1961). Ned.'T. Geneesk., 105, 2241 .

Nilsson, I. M. (1960). Näringsforsk. Fråg., 4, 66.

Schmutzler, R. (1961). Thrombos. Diathes. haemorrh. (Stuttg.), 5, 566. van Creveld, S., and Mochtar, I. A. (1961). Ann. paediat. (Basel), 197, 1. van Creveld, and Koppe, J. G. (1965). Ibid., 202, 1

Verstraete, M., Vermylen, C., and Devreker, R. (1962). Proceedings of Eighth Congress of European Society of Haematology, Vienna, 1961, comm. 358. Basel.

\title{
Effect of Vagotomy on Gastric Acid Secretion Stimulated by Pentagastrin and Histamine
}

\author{
R. A. PAYNE,* M.S., F.R.C.S. ; ALAN G. COX, $†$ M.D., F.R.C.S.ED. ; JOHN SPENCER, $\ddagger$ M.B., B.S., F.R.C.S. \\ F. C. Y. CHENG, $\S$ M.B., B.S., F.R.C.S., F.R.C.S.ED.
}

Brit. med. F., 1967, 4, 456-457

The study of human gastric acid secretion has been hindered by lack of a readily available agent which has the properties of gastrin and which can be administered to man with safety. Hog antral mucosa has provided a source of gastrin for animal experimentation, but until isolated in a pure form by Gregory and Tracy (1964) gastrin has not been available for use in man. The production of pure gastrin on a commercial scale has not proved practicable. However, since the introduction of a synthetic substance known as pentagastrin (Peptavlon, I.C.I.) the physiological properties of gastrin can be studied. This is a pentapeptide with a terminal tetrapeptide which appears to be the physiologically active constituent of gastrin (Tracy and Gregory, 1964).

The present investigation was undertaken to compare the effect of vagotomy (with pyloroplasty) on the maximal gastric responses to stimulation by histamine and by pentagastrin. Histamine has been widely used to study acid secretion, but it may now be superseded by pentagastrin. It is therefore important to determine if the results of investigations with pentagastrin can be compared with those of previous work with histamine.

\section{Method of Study}

Fifteen patients with uncomplicated chronic duodenal ulcer were studied before and after total vagotomy with pyloroplasty. Before operation the maximal acid responses to histamine and to pentagastrin were measured on two separate days. Seven to 10 days after operation an insulin test was performed to confirm the completeness of vagotomy, and the two tests with

* Consultant Surgeon, North Middlesex Hospital, London N.18 ; Honorary Lecturer in Surgery, Royal Postgraduate Medical School, London ary L. L.

t Lecturer in Surgery, Royal Postgraduate Medical School ; Consultant Surgeon, Hammersmith Hospital, London W.12.

Tutor in Surgery, Royal Postgraduate Medical School ; Senior Registrar, Hammersmith Hospital, London W.12.

Honorary Registrar. Hammersmith Hospital ; Lecturer in Surgery, University of Hong Kong. histamine and pentagastrin were then repeated on successive days.

All secretory tests were carried out in the morning after an overnight fast. Before operation a 16 French gauge nasogastric tube was passed into the most dependent part of the stomach under $x$-ray control. In the postoperative tests use was made of a double-lumen feeding gastrostomy tube for collection of the gastric secretions. The tube was placed at operation with one limb in the dependent part of the stomach and the other in the duodenum (Burns and Menzies, 1966). In all tests gastric juice was aspirated continuously by an electric pump at a subatmospheric pressure of $5 \mathrm{~cm}$. $\mathrm{Hg}$, and the patency of the tube was checked at frequent intervals throughout each test. The aspirations were collected in 15-minute samples and their total acid content in $\mathrm{mEq}$ was measured by titration with

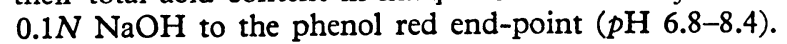

In each test two 15-minute specimens of basal secretion were collected after aspiration of the fasting juice. The tests then continued as follows:

Maximal Histamine Response.-Histamine acid phosphate was infused intravenously at a rate of $40 \mu \mathrm{g} . / \mathrm{kg}$./hour (Lawrie et al., 1964) for 120 minutes. The maximal response was taken as the sum of the four consecutive samples giving the highest total.

Maximal Pentagastrin Response.-Pentagastrin was infused intravenously at a rate of $6 \mu \mathrm{g} . / \mathrm{kg} . /$ hour for 90 minutes, which is sufficient to give a steady level of secretion (Multicentre Pilot Study, 1967). The maximal response was calculated as for the histamine test.

Insulin Test.-Soluble insulin, $0.25 \mathrm{unit} / \mathrm{mg}$., was injected in a single intravenous dose and completeness of vagotomy was accepted if the concentration of acid in the next two hours failed to rive by more than $20 \mathrm{mEq}$ /litre above the basal concentration.

\section{Results}

Table I shows the maximal response to histamine and pentagastrin before and after vagotomy in each patient. All 15 patients showed a substantially reduced response to boih 